\title{
Analysis of effective resistance calculation methods and their effect on modelling evapotranspiration in two different patches of vegetation in semi-arid SE Spain
}

\author{
A. Were ${ }^{1,2}$, L. Villagarcía ${ }^{3}$, F. Domingo ${ }^{2,4}$, L. Alados-Arboledas ${ }^{1,5}$, and J. Puigdefábregas ${ }^{2}$ \\ ${ }^{1}$ Departamento de Física Aplicada, Universidad de Granada, 18071, Granada, Spain \\ ${ }^{2}$ Estación Experimental de Zonas Áridas, Consejo Superior de Investigaciones Científicas, 04001, Almería, Spain \\ ${ }^{3}$ Departamento de Sistemas Físicos, Químicos y Naturales, Universidad Pablo de Olavide, 41013, Sevilla, Spain \\ ${ }^{4}$ Departamento de Biología Vegetal y Ecología, Universidad de Almería, 04120, Almería, Spain \\ ${ }^{5}$ Centro Andaluz de Medio Ambiente, Universidad de Granada, Junta de Andalucía, 18071, Granada, Spain
}

Received: 18 January 2007 - Published in Hydrol. Earth Syst. Sci. Discuss.: 21 February 2007

Revised: 5 June 2007 - Accepted: 31 August 2007 - Published: 4 September 2007

\begin{abstract}
Effective parameters are of major importance in modelling surface fluxes at different scales of spatial heterogeneity. Different ways to obtain these effective parameters for their use in meso-scale and GCM models have been studied. This paper deals with patch-scale heterogeneity, where effective resistances were calculated in two patches with different vegetation (Retama sphaerocarpa (L.) Boiss shrubs, and herbaceous plants) using different methods: aggregating soil and plant resistances in parallel, in series or by an average of both. Effective aerodynamic resistance was also calculated directly from patch fluxes. To assess the validity of the different methods used, the Penman-Monteith equation was used with effective resistances to estimate the total $\lambda E$ for each patch. The $\lambda E$ estimates found for each patch were compared to Eddy Covariance system measurements. Results showed that for effective surface resistances, parallel aggregation of soil and plant resistances led to $\lambda E$ estimates closer to the measured $\lambda E$ in both patches (differences of around $10 \%$ ). Results for effective aerodynamic resistances differed depending on the patch considered and the method used to calculate them. The use of effective aerodynamic resistances calculated from fluxes provided less accurate estimates of $\lambda E$ compared to the measured values, than the use of effective aerodynamic resistances aggregated from soil and plant resistances. The results reported in this paper show that the best way of aggregating soil and plant resistances depends on the type of resistance, and the type of vegetation in the patch.
\end{abstract}

Correspondence to: A. Were

(ana@eeza.csic.es)

\section{Introduction}

Spatial heterogeneity in surface energy flux modelling, both for hydrological and meteorological purposes, is a subject of intensive research. More specifically, it is important to study how subgrid-scale heterogeneity can be averaged when modelling the surface fluxes in meso-scale models and GCMs.

One of the main surface fluxes is evapotranspiration, or in terms of energy, latent heat flux $(\lambda E)$. It can be estimated by considering that water vapour flows through a gradient of concentrations between the surface and the air, and is controlled by a set of surface and aerodynamic resistances from the different sources of evapotranspiration. Depending on the scale of heterogeneity under study, the sources of evapotranspiration that should be considered vary. In sparse-vegetation, or patch-scale heterogeneity, the plant is the roughness element that produces the surface heterogeneity. Therefore, with patch-scale heterogeneity, soil and plants are the sources of evapotranspiration considered, each with its own surface and aerodynamic resistances. At this scale, $\lambda E$ can be estimated using sparse-vegetation models (examples of these models are Dolman, 1993; Brenner and Incoll, 1997; Domingo et al., 1999; Verhoef and Allen, 2000). These models assume that soil and plant fluxes interact at the mean canopy source height $\left(z_{m}\right)$, above which an aerodynamic resistance between this height and the reference height above the vegetation $\left(z_{r}\right)$ must be taken (named the atmospheric aerodynamic resistance).

At larger scales (micro- and meso-scale heterogeneity according to Mahrt, 2000), heterogeneity comes from the presence of different patches of vegetation. When modelling $\lambda E$

Published by Copernicus Publications on behalf of the European Geosciences Union. 
at this scale, each patch can be considered a source of $\lambda E$, each with its own effective resistances (Blyth, 1995). This brings us to the concept of the effective parameter (Fiedler and Panofsky, 1976), defined as that parameter which provides the same flux as the flux that would be calculated from contributions of individual patches, each with their own parameter (Dolman and Blyth, 1997). In this work, we used effective parameters, more specifically, patch-scale effective resistances. According to the above definition of the effective parameter, patch-scale effective resistances should provide the total patch flux.

We have calculated the effective resistances $\left(r^{e}\right)$ in two patches with different vegetation, using different methods, aggregating soil and plant resistances following the methods introduced by Blyth et al. (1993), and calculating them directly from the fluxes in the patch (Blyth, 1997; Verma, 1989). In the case of the aggregation of resistances, many authors have addressed the issue of aggregating the resistances at subgrid-scale to obtain effective aggregated resistances at grid-scale. Some authors have developed theory approaches for aggregating resistances that require subgridscale information (i.e. Raupach, 1995), while other authors have used aggregation rules based on the blending height theory (Wieringa, 1986; Mason, 1988) to estimate the aggregated grid-scale parameters (i.e. Shuttleworth et al., 1997; Arain et al., 1997). However, Blyth et al. (1993) developed more empirical aggregation rules, that due to their simplicity were the ones considered in this work to obtain the aggregated patch-scale effective resistances.

To assess the validity of the different methods used, a Penman-Monteith equation (Monteith, 1965) was used with effective resistances to estimate the total $\lambda E$ in each patch. The estimates of $\lambda E$ obtained for each patch were compared with Eddy Covariance system measurements.

\section{Theory}

Different methods have been developed to calculate effective resistance $\left(r^{e}\right)$. Some methods are based on aggregation of local resistances, either using a probability density function (Dolman, 1992), simple area-weighted aggregations (Blyth et al., 1993; Noilhan et al., 1997; Chehbouni et al., 2000) or more complex averaging schemes (McNaughton, 1994; Shuttleworth et al., 1997; Arain et al., 1997). Other methods estimate the effective resistances at a given heterogeneous scale from the variables and fluxes measured at that scale (Blyth, 1997; Verma, 1989). In this paper we used both approaches: the aggregation of the soil and plant resistances and the estimation of the aerodynamic resistances from the fluxes measured in each patch.
2.1 Aggregation of soil and plant resistances to calculate patch-scale effective resistances

The simplest way to find the aggregated effective resistances $\left(\left\langle r^{e}\right\rangle\right)$ at a given scale of heterogeneity is to aggregate the resistances at the smaller scale $\left(r^{i}\right)$, following Ohm's Law, either in parallel:

$\frac{1}{\left\langle r^{e}\right\rangle_{p}}=\overline{\left(\frac{1}{r^{i}}\right)}$

or in series:

$$
\left\langle r^{e}\right\rangle_{s}=\overline{r^{i}}
$$

Though it is clear that surface and aerodynamic resistances from a given source must be in series (Jones, 1992), it is not clear how soil and plant resistances are related to each other. According to Blyth et al. (1993), the aggregation of resistances recommended varies depending on the flux. These authors state that for momentum, the resistances of a heterogeneous surface are set in parallel and the resulting $\left\langle r^{e}\right\rangle$ is weighted towards the lowest resistance. For sensible heat, the resistances are set in series and the resulting $\left\langle r^{e}\right\rangle$ is weighted towards the highest resistance. However, the authors find that these approximations do not always work, and that the correct $\left\langle r^{e}\right\rangle$ should be an average weighted by the flux. This has the disadvantage of needing to know the fluxes before calculating the effective resistances. For $\lambda E$ fluxes, these authors proposed a practical way to find more accurate $\left\langle r^{e}\right\rangle$ by averaging the resistances obtained with Eqs. (1) and (2):

$$
\left\langle\overline{r^{e}}\right\rangle=\frac{1}{2}\left\{\left\langle r^{e}\right\rangle_{s}+1 /\left(\frac{1}{\left\langle r^{e}\right\rangle_{p}}\right)\right\}
$$

This approximation has also been used by other authors to calculate $\left\langle r^{e}\right\rangle$ (both surface and aerodynamic) for $\lambda E$ (Dolman and Blyth, 1997).

Blyth et al. (1993) approximations are proposed for mesoscale and GCM models, but at patch-scale in sparsely vegetated areas, where soil and plant resistances are to be aggregated, it is not clear what kind of aggregation rules apply. Therefore, in this study, we used all three kinds of aggregation: parallel, series and an average of both (see Material and methods section).

\subsection{Calculation of patch-scale effective resistances from fluxes}

The second approach for estimating $r^{e}$ at a certain heterogeneous scale is to calculate it from fluxes at that scale. The equations used vary for surface and aerodynamic resistances.

Effective surface resistances $\left(r_{s}^{e}\right)$ can be obtained from the Penman-Monteith equation (Eq. 6). Calculating $r_{s}^{e}$ this way has the disadvantage of having to know $\lambda E$ first, though it is used to model the fluxes at a higher scale when smaller scale fluxes are known (Blyth, 1997). This method was not used in 
our work, as we wanted to estimate patch $\lambda E$ with the same Penman-Monteith equation used to find the resistances.

Effective aerodynamic resistances $\left(r_{a}^{e}\right)$ can be calculated from the patch aerodynamic parameters and friction velocity $\left(u_{*}\right)$ with the equation proposed by Verma (1989) and used by other authors (Blyth, 1997; Dolman and Blyth, 1997). Assuming neutral atmospheric conditions, the aerodynamic resistance from the surface to a given reference height $\left(z_{r}\right)$, can be calculated as follows (Verma, 1989):

$r_{a}=\frac{u_{r}}{u_{*}^{2}}+\frac{k B^{-1}}{k u_{*}}$

where $r_{a}$ is equivalent to the patch $r_{a}^{e}, u_{r}$ is the wind speed at $z_{r}, u_{*}$ is the friction velocity and $k B^{-1}$ is equivalent to:

$k B^{-1}=\ln \left(\frac{z_{0}}{z_{h}}\right)$

where $k$ is the von Kármán's constant, $B^{-1}$ is a dimensionless parameter proposed by Owen and Thompson (1963), and $z_{0}$ and $z_{h}$ are the roughness lengths for momentum and sensible heat, respectively. Parameter $k B^{-1}$ is considered constant, especially for homogeneous areas. However, $k B^{-1}$ measurements in different areas of sparse heterogeneous vegetation vary greatly, depending on surface temperature, solar radiation or on vegetation features (Kustas et al., 1989; Brutsaert, 1979; Van den Hurk and McNaughton, 1995; Qualls and Brutsaert, 1995). Different parameterizations have been made relating $k B^{-1}$ to the Reynolds number or $u_{*}$ (Mölder and Lindroth, 2001). Nevertheless, some authors have found good results for different surfaces using a $k B^{-1}$ of approximately 2, which means that $z_{0}$ is 10 times higher than $z_{h}$ (Garrat, 1978; Dolman and Blyth, 1997; Mölder and Lindroth, 2001; Verma, 1989). As explained in the Material and methods section, we used two different values for $k B^{-1}$, one generic as proposed by Verma (1989), and one measured.

Calculating $r_{a}^{e}$ this way has the advantage that soil and plant resistances need not be known in advance, thus avoiding the need for their measurement and parameterization.

2.3 Estimation of patch-scale $\lambda E$ with the effective resistances

As commented above, according to the definition of the effective parameter, the use of patch-scale effective resistances should provide accurate estimates of patch $\lambda E$. We used a Penman-Monteith equation to estimate the patch $\lambda E$, as follows:

$\lambda E=\frac{\Delta A+\left(\rho c_{p} D_{a} / r_{a}^{e}\right)}{\Delta+\gamma\left(1+r_{s}^{e} / r_{a}^{e}\right)}$

where $A$ is the available energy, $\rho$ is the air water vapour density at $z_{r}, c_{p}$ is the specific heat of air, $\Delta$ is the slope of the curve relating saturated air water vapour pressure to temperature, $\gamma$ is the psychrometric constant and $D_{a}$ is the

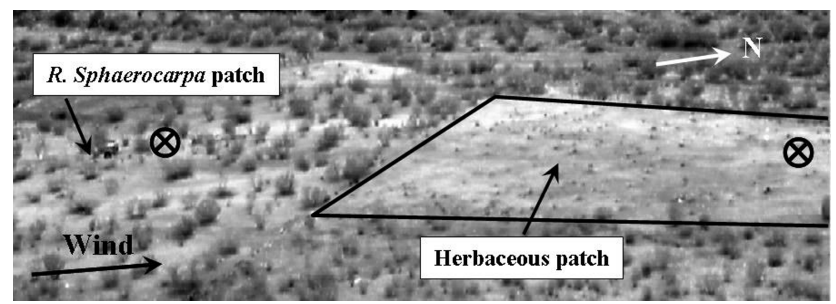

Fig. 1. View from the east of the two vegetation patches on the valley floor. The predominant wind speed direction and North are indicated. The location of the Eddy Covariance system in each patch is marked by a cross.

water vapour pressure deficit at $z_{r} . r_{s}^{e}$ and $r_{a}^{e}$ are the effective surface and aerodynamic resistances of each patch, calculated with the different methods described in the Material and methods section as mentioned above.

\section{Material and methods}

Field experiments for measuring the aerodynamic and surface resistances of soil and plants, and the different micrometeorological variables and $\lambda E$, were carried out in two patches of sparse semi-arid vegetation characteristic of southeastern Spain.

\subsection{Site description}

The field site is located in Rambla Honda, a dry valley near Tabernas, Almería, Spain $\left(37^{\circ} 8^{\prime} \mathrm{N}, 2^{\circ} 22^{\prime} \mathrm{W}, 630 \mathrm{~m}\right.$ altitude). The field site has previously been described in detail elsewhere (see e.g., Puigdefábregas et al., 1996, 1998, 1999; Domingo et al., 1999, 2001). The valley bottom is a dry river bed with deep loamy soils that overlay mica- schist bedrock, dominated by Retama sphaerocarpa (L.) Boiss shrubs separated by bare areas dominated by herbaceous species.

The field site has an average annual rainfall of $220 \mathrm{~mm}$, average mean temperature of $16^{\circ} \mathrm{C}$ and a dry season from around June to September.

The patches selected were located on the east bank of the dry river bed on the valley floor. A $10^{4} \mathrm{~m}^{2}$ patch was selected in which all the $R$. sphaerocarpa was cut, leaving a patch with only the herbaceous stratum (Fig. 1).

$R$. sphaerocarpa is a woody leguminous shrub with ephemeral leaves and cylindrical photosynthetic stems (cladodes), which grows up to $4 \mathrm{~m}$ tall and $6 \mathrm{~m}$ diameter. It has an open canopy structure and deep root system which can extract water from depths of more than $25 \mathrm{~m}$ (Domingo et al., 1999, 2001; Haase et al., 1996). Growth starts in March, flowering is in May, and fructification is from July to September. New shoots germinate in January and February. The average fractional vegetative cover $(f)$ of the $R$. sphaerocarpa patch was 0.17 , and the average leaf area index $(L)$ of the $R$. sphaerocarpa plants was $0.81 \mathrm{~m}^{2} \mathrm{~m}^{-2}$. 
a)

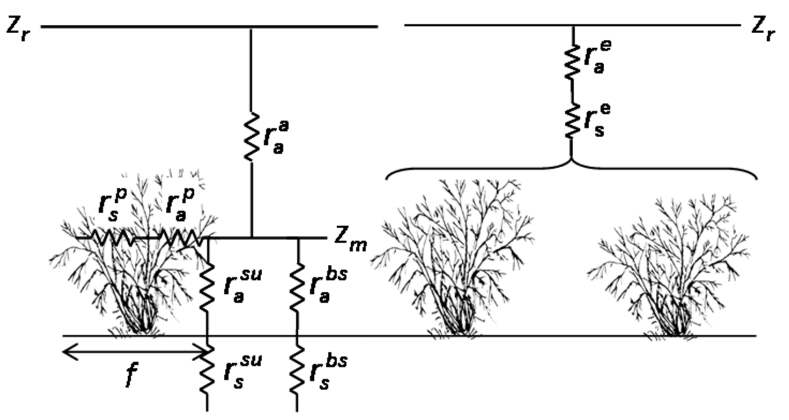

b)

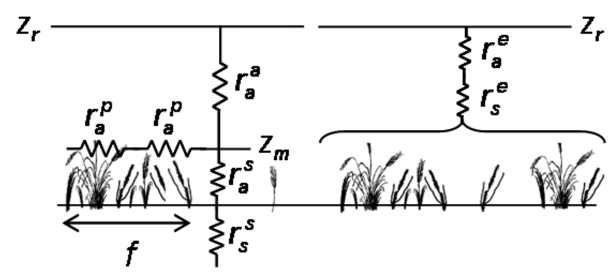

Fig. 2. Scheme showing the soil, plant and atmospheric resistances and the effective resistances $\left(r^{e}\right)$ considered for each patch. (a) $R$. sphaerocarpa patch, (b) Herbaceous patch. See text for an explanation of symbols.

The herbaceous species are predominantly annuals or therophytes, with few hemicryptophytes or cryptophytes (Gutiérrez, 2000). The maximum biomass is reached in spring, between March and May, though this varies in different years. The growing period starts in October or November, after the first rains, and continues until March or April. Flowering is from February to April, and fructification from March to May. During the summer there are practically no herbaceous plants. Herbaceous phenology is very sensitive to precipitation in fall and spring, so the periods of growth, flowering, fructification and senescence may vary in different years (Gutiérrez, 2000), and is also the reason why the average $f$ of the herbaceous patch varied during the experiment.

\subsection{Measurement and parameterization of soil and plant re- sistances}

Several field experiments were performed to measure and parameterize the soil and plant resistances in the two patches.

As shown in Fig. 2a, in the $R$. sphaerocarpa patch, the surface resistances considered were for plant $\left(r_{s}^{p}\right)$, soil under plant $\left(r_{s}^{s u}\right)$ and bare soil $\left(r_{s}^{b s}\right)$, and their respective aerodynamic resistances $\left(r_{a}^{p}, r_{a}^{s u}\right.$ and $\left.r_{a}^{b s}\right)$. As mentioned in the Introduction, an aerodynamic resistance between the mean canopy source height $\left(z_{m}=z_{0}+d\right)$ and the reference height $\left(z_{r}\right)$, referred to here as the atmospheric aerodynamic resistance $\left(r_{a}^{a}\right)$, was also considered. In the herbaceous patch (Fig. 2b), only one soil surface resistance and one soil aerodynamic resistance were considered $\left(r_{s}^{s}\right.$ and $r_{a}^{s}$, respectively), as any difference between soil under plant and bare soil was neglected. The rest of the resistances were the same as in the other patch.

Soil surface and aerodynamic resistances, as well as plant surface resistances, were measured in different positions, and then averaged to obtain the soil and plant resistances of the patch.

$r_{s}^{s}, \quad r_{s}^{s u}$ and $r_{s}^{b s}$ were measured with microlysimeters following the methodology proposed by Daamen et al. (1993). 6 microlysimeters were installed in the case of the herbaceous patch, and 12 (6 under plant and 6 in bare soil) in the $R$. sphaerocarpa patch. The averaged values were related to soil moisture $(\theta)$ from which different parametric equations were obtained (see Table 1). This method has also been used successfully by Domingo et al. (1999) in the Rambla Honda field site to estimate soil surface resistances in another patch of $R$. sphaerocarpa close to the one described in this paper.

Soil aerodynamic resistances were measured using the energy balance of paired heated sensors method developed by McInnes et al. (1994, 1996). In the herbaceous patch were located 3 pairs of sensors, while in the $R$. sphaerocarpa patch there were 4 pairs of sensors placed in a gradient from under plant to bare soil (according to Domingo et al., 1999). In the herbaceous patch, averaged $r_{a}^{s}$ was related to wind speed at $z_{r}\left(u_{r}\right)$, to find a parametric equation for it (Table 1). In the $R$. sphaerocarpa patch, the parametric equations relating $r_{a}^{s u}$ and $r_{a}^{b s}$ to $u_{r}$ were those obtained by Domingo et al. (1999) using the same methodology (Table 1).

Plant resistance $r_{s}^{p}$ was calculated from its opposite, plant conductance $\left(g_{s}^{p}\right)$, which is related to leaf conductance $\left(g_{s}^{l}\right)$ as follows:

$1 / r_{s}^{p}=g_{s}^{p}=2 g_{s}^{l} L$

$g_{s}^{l}$ measurements in the herbaceous patch were taken with a porometer with an IRGA (LCA-3, ADC, Hoddesdon, UK) and a PLC-3 chamber (ADC, Hoddeson, UK). Measurements were made in three leaves of three different species of herbaceous plants (which differed during the measuring period). The measurements made in each leaf were averaged to obtain a value of leaf conductance for each species, and these values were averaged to obtain the leaf conductance of the herbaceous plants of the patch. The averaged patch values were related to $D_{a}$ obtaining the parametric equation used for the herbaceous patch (Table 2).

The parametric equations used for $R$. sphaerocarpa relating this conductance to photosynthetically active radiation flux $(Q), D_{a}$ and $\theta$ were those found by Brenner and Incoll (1997) at the same site. According to Baldocchi et al. (1991) $g_{s}^{l}$ can be calculated as:

$g_{s}^{l}=g_{s}^{m} Q /\left(Q+b_{q}\right)$

where $g_{s}^{m}$ is the maximum $g_{s}^{l}$ at light saturation dependent on $D_{a}$ :

$g_{s}^{m}=g_{s}^{\max }+b_{d} D_{a}$ 
Table 1. Equations relating soil surface resistances $\left(r_{s}^{s}, r_{s}^{s u}\right.$ and $\left.r_{s}^{b s}\right)$ to soil moisture $(\theta)$ and soil aerodynamic resistances $\left(r_{a}^{s}, r_{a}^{s u}\right.$ and $\left.r_{a}^{b s}\right)$ to wind speed at reference height $\left(u_{r}\right)$, for the two patches studied.

\begin{tabular}{lcccccc}
\hline & $r_{s}^{s}$ & $r_{s}^{s u}$ & $r_{s}^{b s}$ & $r_{a}^{s}$ & $r_{a}^{s u}$ & $r_{a}^{b s}$ \\
\hline $\begin{array}{l}\text { R. sphaerocarpa } \\
\text { Herbaceous }\end{array}$ & $0.14 \theta^{-3.8}$ & $7.74 \theta^{-1.95}$ & $0.45 \theta^{-3}$ & & $98.4 u_{r}^{-0.17}$ & $73.7 u_{r}^{-0.19}$ \\
\hline
\end{tabular}

Table 2. Equations relating the coefficients $g_{s}^{\max }$ and $b_{d}$ to soil moisture $(\theta)$ obtained by Brenner and Incoll (1997) for $R$. sphaerocarpa; and equation relating surface leaf conductance $\left(g_{S}^{l}\right)$ to water vapour pressure deficit $\left(D_{a}\right)$ for herbaceous plants.

\begin{tabular}{lccc}
\hline & $g_{s}^{\max }$ & $b_{d}$ & $g_{s}^{l}$ \\
\hline $\begin{array}{l}\text { R. sphaerocarpa } \\
\text { Herbaceous }\end{array}$ & $-1.38 \theta-0.1$ & $3.25 \theta+0.34$ & \\
\hline
\end{tabular}

Brenner and Incoll (1997) related the daily average of the measured conductance to $D_{a}$ on different days, and $g_{s}^{\max }$ (maximum $g_{s}^{l}$ at light saturation and air water vapour saturation) and $b_{d}$ (indicator of $g_{s}^{l}$ changes with $D_{a}$ ) were related to $\theta$ (see equations in Table 2).

Once $g_{s}^{m}$ is known, and considering that $Q$ decreases through the canopy by the coefficient of extinction of the canopy $(\kappa), g_{s}^{p}$ is calculated as (Shuttleworth and Gurney, 1990):

$g_{s}^{p}=\left(g_{s}^{m} / \kappa\right) \ln \left[\left(b_{q}+\kappa Q\right) /\left(b_{q}+\kappa Q e^{\kappa L}\right)\right]$

where $b_{q}$ is the coefficient of linearity between the values of $g_{s}^{l}$ measured and estimated with Eq. (8) $\left(b_{q}=200 \mathrm{~mol} \mathrm{~m}^{-2} \mathrm{~s}^{-1}\right)$.

$r_{a}^{p}$ was calculated following the equations proposed by Shuttleworth and Wallace (1985) and Choudhoury and Monteith (1988). Similar to Eq. (7):

$r_{a}^{p}=r_{a}^{l} / 2 L$

where $r_{a}^{l}$ is the average leaf aerodynamic resistance of the canopy leaves, calculated as:

$r_{a}^{l}=(n / a)\left(w / u_{h}\right)^{0.5}\left(1-e^{(-n / 2)}\right)^{-1}$

where $a$ is a constant that relates $r_{a}^{l}$ with $u_{h}$ (Domingo et al., 1996), $w$ is the average width of the leaves and $u_{h}$ is the wind speed above vegetation, calculated as:

$u_{h}=\left(u_{*} / k\right) \ln \left[(h-d) / z_{0}\right]$

where $h$ is the height of vegetation, $d$ is the displacement height, $z_{0}$ is the roughness length, and $u_{*}$ is the friction velocity calculated as:

$u_{*}=k u_{r} / \ln \left[\left(z_{r}-d\right) / z_{0}\right]$
Table 3. Reference height $\left(z_{r}\right)$, vegetation height $(h)$, leaf area index $(L)$ and fractional vegetation cover $(f)$, for each vegetation patch. All values in meters, except $L$ (in $\mathrm{m}^{2} \mathrm{~m}^{-2}$ ) and $f$ (unitless).

\begin{tabular}{lllll}
\hline & $\mathrm{z}_{r}$ & $h$ & $L$ & $f$ \\
\hline R. sphaerocarpa & 4.4 & 2.26 & 0.81 & 0.17 \\
Herbaceous & 2.5 & 0.22 & & \\
\hline
\end{tabular}

$r_{a}^{a}$ was also calculated with theoretical equations developed by Shuttleworth and Gurney (1990). In the end, $r_{a}^{a}$ is calculated as:

$$
\begin{aligned}
r_{a}^{a}= & \left(1 / k u_{*}\right) \ln \left[\left(z_{r}-d\right) /(h-d)\right](1+\delta)^{\varepsilon}+\left(h / n K_{h}\right) \\
& {\left[e^{\left\{n\left[1-\left(z_{o}+d\right) / h\right]\right\}}-1\right] }
\end{aligned}
$$

where $K_{h}$ is the turbulent diffusion coefficient for water vapour above the vegetation, $n$ is the coefficient indicating the decrease in the turbulent diffusion through the vegetation, and $(1+\delta)^{\varepsilon}$ is a correction factor for the stability atmospheric conditions. $z_{0}$ and $d$ were calculated with the equations used by Shuttleworth and Gurney (1990) relating these parameters to the $L_{p}$ (patch leaf area index $=L / f$ ) and $h$.

Table 3 shows the values of the vegetation parameters needed to calculate these resistances. $L$ and $f$ in the herbaceous patch were estimated from biomass measurements. $f$ ranged from 0 (near summer) to 0.4 (in spring), depending on the phenology of the plants in the patch. An equation relating $L$ to $f$ was obtained: $L=5.8 f^{0.78}\left(R^{2}=0.99, n=8\right)$. In the $R$. sphaerocarpa patch, $L$ was measured in individual $R$. sphaerocarpa plants with a Sunscan system (Delta Devices Ltd., Cambridge, UK) and averaged. $f$ was calculated from measurements of the projected plant canopy area in selected stands in the patch.

\subsection{Calculating the effective resistances $\left(r^{e}\right)$ for each patch}

As mentioned above in the Theory section, one of the methods used to calculate the surface and aerodynamic effective resistances for each patch, $r_{s}^{e}$ and $r_{a}^{e}$ (Fig. 2), was to aggregate soil and plant resistances, thus obtaining the effective aggregated surface and aerodynamic resistances, $\left\langle r_{s}^{e}\right\rangle$ and $\left\langle r_{a}^{e}\right\rangle$. 
In the case of $\left\langle r_{a}^{e}\right\rangle$, we aggregated the aerodynamic resistances of soil and plant, and also the atmospheric aerodynamic resistance, as $\left\langle r_{a}^{e}\right\rangle$ represents the total aerodynamic resistance from soil to reference height $\left(z_{r}\right)$ (Fig. 2). Therefore $\left\langle r_{a}^{e}\right\rangle$ was calculated aggregating soil and plant aerodynamic resistances, weighted by $f$, either in series or in parallel, while $r_{a}^{a}$ was always aggregated in series as this is its position relative to the other aerodynamic resistances (Fig. 2). Therefore the equations for the $R$. sphaerocarpa patch were:

$$
\begin{aligned}
& \left\langle r_{a}^{e}\right\rangle_{p}=\left(f\left(\frac{1}{r_{a}^{p}}+\frac{1}{r_{a}^{s u}}\right)+(1-f)\left(\frac{1}{r_{a}^{b s}}\right)\right)^{-1}+r_{a}^{a} \\
& \left\langle r_{a}^{e}\right\rangle_{s}=f\left(r_{a}^{p}+r_{a}^{s u}\right)+(1-f) r_{a}^{b s}+r_{a}^{a}
\end{aligned}
$$

and for the herbaceous patch:

$$
\begin{aligned}
& \left\langle r_{a}^{e}\right\rangle_{p}=\left(f\left(\frac{1}{r_{a}^{p}}\right)+(1-f)\left(\frac{1}{r_{a}^{s}}\right)\right)^{-1}+r_{a}^{a} \\
& \left\langle r_{a}^{e}\right\rangle_{s}=f r_{a}^{p}+(1-f) r_{a}^{s}+r_{a}^{a}
\end{aligned}
$$

In the case of $\left\langle r_{s}^{e}\right\rangle$, we also aggregated the surface soil and plant resistances, weighed by $f$, either in parallel or in series. The equations for the $R$. sphaerocarpa patch were:

$$
\begin{aligned}
\frac{1}{\left\langle r_{s}^{e}\right\rangle_{p}} & =f\left(\frac{1}{r_{s}^{p}}+\frac{1}{r_{s}^{s u}}\right)+(1-f)\left(\frac{1}{r_{s}^{b s}}\right) \\
\left\langle r_{s}^{e}\right\rangle_{s} & =f\left(r_{s}^{p}+r_{s}^{s u}\right)+(1-f) r_{s}^{b s}
\end{aligned}
$$

and for the herbaceous patch:

$$
\begin{aligned}
\frac{1}{\left\langle r_{s}^{e}\right\rangle_{p}} & =f\left(\frac{1}{r_{s}^{p}}\right)+(1-f)\left(\frac{1}{r_{s}^{s}}\right) \\
\left\langle r_{s}^{e}\right\rangle_{s} & =f r_{s}^{p}+(1-f) r_{s}^{s}
\end{aligned}
$$

In all equations $\left\langle r^{e}\right\rangle_{s}$ and $\left\langle r^{e}\right\rangle_{p}$ refer to effective resistances aggregated in series and in parallel, respectively.

We also averaged the effective resistances aggregated in parallel and in series (Eq. 3) to find the average aggregated effective surface and aerodynamic resistances, $\left\langle\overline{r_{s}^{e}}\right\rangle$ and $\left\langle\overline{r_{a}^{e}}\right\rangle$, for each patch.

The other calculation method, mentioned above in the Theory section, was only used in this paper for the effective aerodynamic resistance $\left(r_{a}^{e}\right)$ (Eq. 4). Two different values of $k B^{-1}$ were used to calculate $r_{a}^{e}$ for each patch: i) 2.3 as proposed by Verma (1989) and used by some authors for heterogeneous surfaces (Blyth, 1997; Dolman and Blyth, 1997), the resulting resistance being referred to as $r_{a_{1}}^{e}$; ii) an averaged value of $9(\mathrm{SD}=6)$ obtained by Alados-Arboledas et al. (2000) from radiometric temperature measurements in a patch of $R$. sphaerocarpa in the Rambla Honda field site, the resulting resistance then being referred to as $r_{a_{2}}^{e}$. Friction velocity $\left(u_{*}\right)$ was calculated using Eq. (14).

\subsection{Micrometeorological and energy flux measurements}

Latent $(\lambda E)$ and sensible $(H)$ heat fluxes were measured by an Eddy covariance station in a tower at the reference height in the northern part of each patch, where due to the dominant wind direction, they have the best fetch (Fig. 1). The Eddy covariance systems consisted of a three-dimensional sonic anemometer (CSAT3, Campbell Scientific Inc., USA) and a krypton hygrometer KH20 (CSAT3, Campbell Scientific Inc., USA). $\lambda E$ measurements were corrected for air density fluctuation due to heat and water vapour flux as proposed by Webb et al. (1980). Hygrometer measurements were corrected for absorption of radiation by oxygen, according to Tanner et al. (1993). The rotation of the coordinate system (Kowalski et al., 1997) was unnecessary, because as the terrain is near a river bed, it is almost flat, and it was verified that the values barely change with this correction.

The wind speed and air temperature at reference height $\left(u_{r}\right.$ and $T_{r}$ ) were measured with the sonic anemometer. The water vapour pressure at reference height $\left(e_{r}\right)$ required for calculation of $D_{a}$ was measured with a dew point hygrometer (Dew-10, General Eastern Corp., USA). $R_{n}$ was measured with a radiometer (NR Lite, Kipp and Zonen, Delft, the Netherlands).

Patch soil heat flux $(G)$ was calculated as the sum of the average flux $(F)$ measured with two soil heat flux plates (HFT-3, REBS, Seattle, WA, USA) at a depth of $0.08 \mathrm{~m}$, in each patch, and the heat stored in the layer of soil above the plates $\left(S_{t}\right)$ (Fuchs, 1986; Massman, 1992):

$S_{t}=\Delta T_{s}\left[B_{d}\left(C_{s}+C_{w} \theta\right)\right] D p / t$

where $B_{d}$ is the apparent density of soil $\left(1555 \mathrm{~kg} \mathrm{~m}^{-3}\right.$ according to Puigdefábregas et al., 1996), $C_{s}$ is the specific heat of dry soil, $C_{w}$ is the specific heat of water, $D p$ is the depth at which the soil heat flux plate is located, $t$ is the time lapse between measurements, and $\Delta T_{S}$ is the changing rate of soil temperature between two consecutive measurements by two thermocouples (TCAV, Campbell Scientific Ltd.) at two depths $(0.02 \mathrm{~m}$ and $0.06 \mathrm{~m})$ above each soil heat flux plate. In the case of the $R$. sphaerocarpa stand the soil heat flux plates were located, one on bare soil and the other one on soil under a $R$. sphaerocarpa plant, to consider the variability between bare soil and soil under plant. Therefore, the $G$ of the stand was calculated as an average of the flux obtained for each type of soil weighted by the fractional vegetative cover of the stand.

Soil moisture $(\theta)$ was measured with 6 self-balanced impedance bridge (SBIB) probes in the herbaceous patch, and 12 in the $R$. sphaerocarpa patch in a range of positions from soil under plant to bare soil at a depth of $0.04 \mathrm{~m}$. This soil humidity sensor developed by the Estación Experimental de Zonas Áridas (C.S.I.C., Almería, Spain) (Vidal, 1994; Vidal et al., 1996) has been used in other works (see e.g., Puigdefábregas and Sánchez, 1996; Domingo et al., 2000; Cantón et al., 2004). 
All of the micrometeorological variables and heat fluxes $\left(\lambda E, H, R_{n}, F, u_{r}, T_{r}, e_{r}, \theta\right.$ and $T_{s}$ ) measurements were averaged every $30 \mathrm{~min}$ and recorded in dataloggers (Campbell Scientific Ltd., Logan, UT, USA) from April 2002 (DOY 91) to July 2003 (DOY 198).

\subsection{Data set used}

All measured data were filtered using the following criteria. In the first place, days lacking data for any of the energy fluxes necessary to analyse the energy balance (i.e., $R_{n}$, $G, \lambda E$ and $H$ ) were eliminated. Data with a negative $R_{n}$ were also eliminated, leaving only the data for daylight hours (from 08:00 to 16:00 h), because heat fluxes at night are erratic and difficult to predict. Rainy-day data were eliminated, as condensation forms on the krypton hygrometer, making $\lambda E$ data unreliable. The final dataset selected included daytime $\lambda E$ high enough to be reliable and excluded data with $\lambda E$ near $0 \mathrm{~W} \mathrm{~m}^{2}$, which is typical of cloudy days and during the dry season. The result was a dataset for micrometeorological variables and energy fluxes on discontinuous days between DOY 52 and 71 (11 days for the $R$. sphaerocarpa patch, and 13 days for the herbaceous patch).

To check whether the turbulent fluxes measured by the Eddy covariance systems were representative of the two patches under study, a footprint analysis was done for both patches. For this purpose we used the Flux Source Area Model (FSAM) of Schmid (1994, 1997), widely used as a tool for estimating the source area of Eddy covariance measurements (i.e. Goeckede et al., 2004; Scott et al., 2003; Baldocchi et al., 2001). We calculated the dimensions of the $50 \%$ source areas, for a range of atmospheric stabilities, represented in FSAM by the stability factor $\left(z_{r}-d\right) / L$ (being $L$ the Obukhov length). For the data set used for each patch, $30 \%$ of the data corresponded to neutral conditions $\left(0.01>\left(z_{r}-d\right) / L>-0.01\right)$. In the case of unstable conditions $\left(-0.01>\left(z_{r}-d\right) / L>-0.1\right)$, they corresponded to $60 \%$ and $70 \%$ of the data for the $R$. sphaerocarpa patch and the herbaceous patch, respectively. The remaining $10 \%$ and $5 \%$, respectively, corresponded to very unstable conditions $\left(-0.1>\left(z_{r}-d\right) / L>-0.5\right)$. No stable conditions were found as only diurnal data were used. The FSAM model was run for three values of $\left(z_{r}-d\right) / L$ representative of the three types of stability conditions, and calculated as the median of each range of $\left(z_{r}-d\right) / L$ (the median was used to avoid the effect of extreme values on the averaging). The maximum distance of the 50\% source area isopleths was of $77 \mathrm{~m}$ for the $R$. sphaerocarpa patch, and $65 \mathrm{~m}$ for the herbaceous patch, both obtained for neutral conditions $\left(\left(z_{r}-d\right) / L=-0.006\right.$ and -0.007 for the $R$. sphaerocarpa patch and herbaceous patch, respectively). As the footprint theory indicates, all the points of a source area do not contribute in the same way to the turbulent flux measurements (Schmid, 1994, 1997). The FSAM model also calculates the location of the point of maximum influence (Xmax) of the source area. The values of Xmax

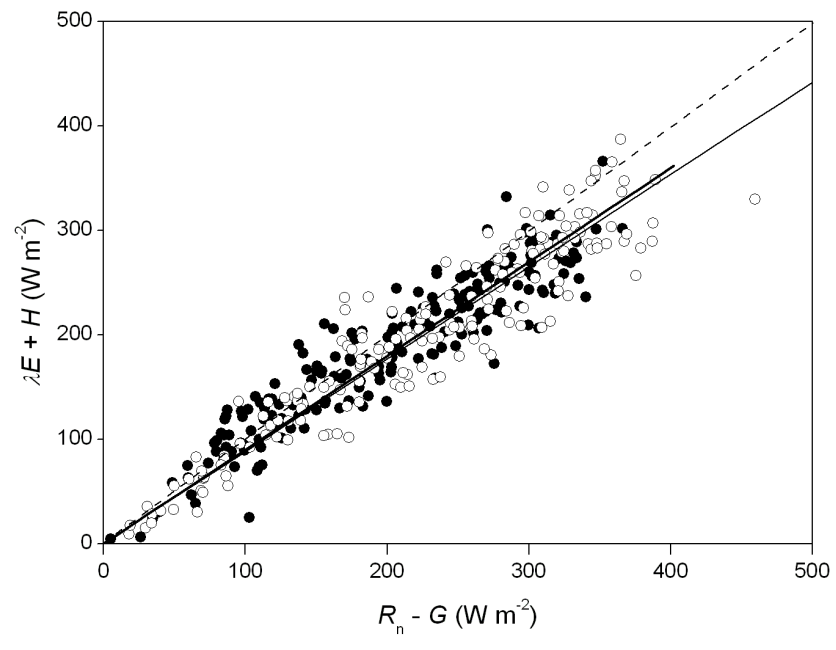

Fig. 3. Comparison of turbulent fluxes $(\lambda E+H)$ and measured available energy $\left(R_{n}-G\right)$ in the two patches studied: $\circ \quad R$. sphaerocarpa patch $(n=177)$; $\bullet$ herbaceous patch $(n=197)$. The regression lines forced through the origin are shown (thin line: R. sphaerocarpa patch; thick line: herbaceous patch), and the 1:1 line (dashed line).

obtained were almost equal for both patches. For neutral conditions, the location of the Xmax was $34 \mathrm{~m}$ away from the tower. For unstable conditions $\left(\left(z_{r}-d\right) / L=-0.03\right.$ and -0.023 for the $R$. sphaerocarpa patch and herbaceous patch, respectively), Xmax was around $30 \mathrm{~m}$ away from the tower. For very unstable conditions $\left(\left(z_{r}-d\right) / L=-0.15\right.$ and -0.13 for the $R$. sphaerocarpa patch and herbaceous patch, respectively) Xmax was around $17 \mathrm{~m}$ away. According to these results the source area of the turbulent fluxes measured in each patch is widely within the patch-area, for all stability conditions. However, due to the position of both Eddy covariance towers, there might be some source areas not representative of each patch for wind directions coming from the North (Fig. 1). However, an analysis of the wind directions of the $30 \mathrm{~min}$ data indicated that only $5 \%$ of the wind directions were within the NW-NE directions, while $80 \%$ of the wind directions were within the SW-SE directions. Therefore, it was considered that the measured turbulent fluxes were highly representative of each patch studied.

To assess the accuracy of the measured $\lambda E$, the energy balance of the fluxes was analysed with a regression between the measured available energy $\left(R_{n}-G\right)$ and the sum of the turbulent fluxes $(\lambda E+H)$ for the period studied (Fig. 3). The data showed an acceptable energy balance closure of nearly $90 \%$ ( $b=0.88, R^{2}=0.89$ for the $R$. sphaerocarpa patch, and $b=0.89$, $R^{2}=0.86$ for the herbaceous patch). 

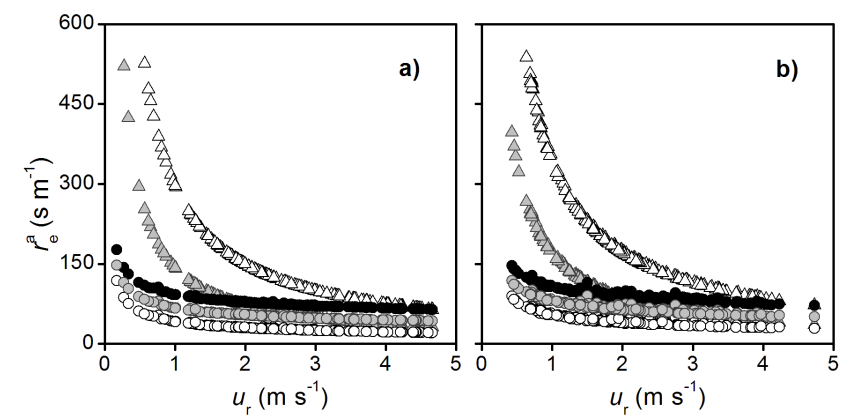

Fig. 4. Effective aerodynamic resistances $\left(r_{a}^{e}\right)$ plotted against the wind speed at reference height $\left(u_{r}\right): r_{a_{1}}^{e}(\triangle), r_{a_{2}}^{e}(\Delta),\left\langle r_{a}^{e}\right\rangle_{p}(\bigcirc)$, $\left\langle r_{a}^{e}\right\rangle_{s}(\bullet)$ and $\left\langle\overline{r_{a}^{e}}\right\rangle(\bigcirc)$. (a) R. sphaerocarpa patch; (b) Herbaceous patch.

\section{Results and discussion}

4.1 Comparison of effective resistances calculated for each patch

To compare the effective resistances calculated, the average percentage difference between them $(\Delta r)$ was found by:

$\Delta r(\%)=\overline{\left(\frac{\left(r_{i}-r_{j}\right)}{r_{i}}\right)} \times 100$

where $r_{i}$ and $r_{j}$ are the resistances compared, and $r_{j}$ is a percentage $\mathrm{X}$ higher (negative) or lower (positive) than $r_{i}$. Table 4 shows the average $\Delta r$ for each patch.

When the effective aerodynamic resistance was compared, the differences between the resistances calculated with Eq. (4) were around $50 \%$ in both patches, with $r_{a_{2}}^{e}$ higher than $r_{a_{1}}^{e}$. When these were compared with the aggregated resistances, $\left\langle r_{a}^{e}\right\rangle_{p}$ was around 50\% lower than $r_{a_{1}}^{e}$ and around $75 \%$ lower than $r_{a_{2}}^{e}$ in both patches. However, the differences between $r_{a_{1}}^{e}$, and $\left\langle r_{a}^{e}\right\rangle_{s}$ and $\left\langle\overline{r_{a}^{e}}\right\rangle$ were not significant, as the SD was very high. $\left\langle r_{a}^{e}\right\rangle_{s}$ was around $40 \%$ lower and $\left\langle\overline{r_{a}^{e}}\right\rangle$ was around $60 \%$ lower than $r_{a_{2}}^{e}$ in both patches. For a better analysis of these differences, the effective aerodynamic resistances were plotted against $u_{r}$ (Fig. 4), since the soil, plant and atmospheric aerodynamic resistances depend on this variable, as well as $r_{a_{1}}^{e}$ and $r_{a_{2}}^{e}$. This figure showed that the differences between $r_{a_{1}}^{e}$, and $\left\langle r_{a}^{e}\right\rangle_{s}$ and $\left\langle\overline{r_{a}^{e}}\right\rangle$ changed with $u_{r}$. At high $u_{r}\left(>2 \mathrm{~m} \mathrm{~s}^{-1}\right)$ the values of $r_{a_{1}}^{e}$ were similar to $\left\langle\overline{r_{a}^{e}}\right\rangle$ and lower than $\left\langle r_{a}^{e}\right\rangle_{s}$. As $u_{r}$ got lower, $r_{a_{1}}^{e}$ got higher than $\left\langle r_{a}^{e}\right\rangle_{s}$ and $\left\langle\overline{r_{a}^{e}}\right\rangle$ (Fig. 4). These results show that $r_{a_{1}}^{e}$ and $r_{a_{2}}^{e}$ were much more sensitive to $u_{r}$ than the aggregated resistances, as the latter also depend on the vegetation parameters $(L, h$ and $f$ ) and on the temperature.

When comparing the aggregated resistances, it was observed that $\left\langle r_{a}^{e}\right\rangle_{p}$ was around $50 \%$ and $60 \%$ lower than $\left\langle r_{a}^{e}\right\rangle_{s}$,
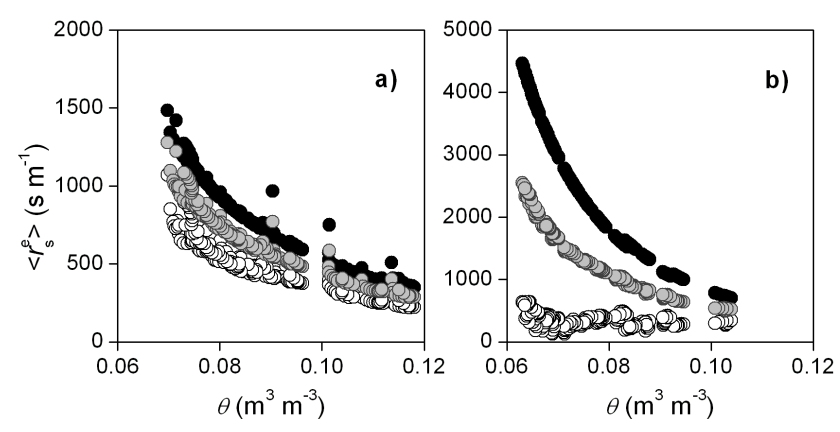

Fig. 5. Effective aggregated surface resistances $\left(\left\langle r_{s}^{e}\right\rangle\right)$ plotted against the soil moisture $(\theta):\left\langle r_{s}^{e}\right\rangle_{p}(\bigcirc),\left\langle r_{s}^{e}\right\rangle_{s}(\bullet)$ and $\left\langle\overline{r_{s}^{e}}\right\rangle(\bigcirc)$. (a) $R$. sphaerocarpa patch; (b) Herbaceous patch.

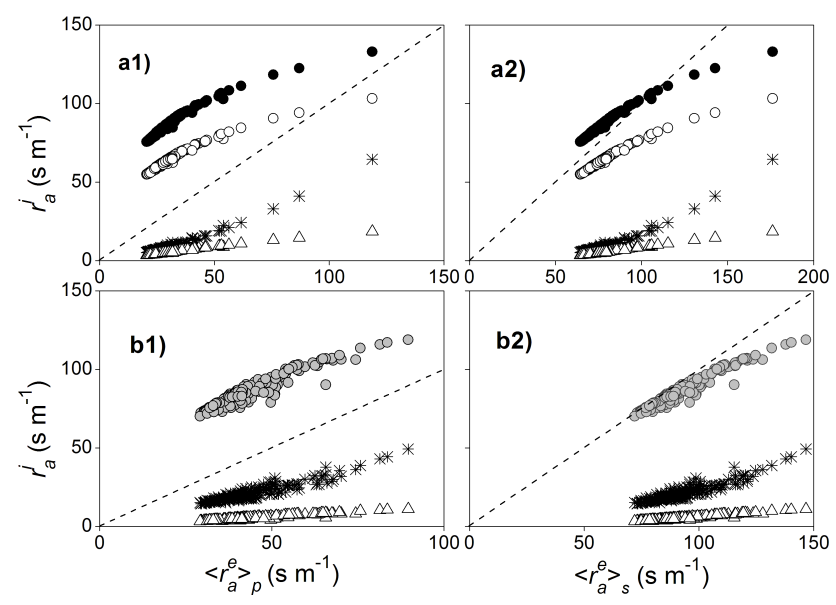

Fig. 6. Aerodynamic resistances of the sources $\left(r_{a}^{s u}: \bullet ; r_{a}^{b s}: \bigcirc\right.$; $\left.r_{a}^{s}: \bigcirc ; r_{a}^{p}: \Delta\right)$ and $r_{a}^{a}(*)$ plotted against the effective aggregated aerodynamic resistances: $\left\langle r_{a}^{e}\right\rangle_{p}$ (a1 and b1) and $\left\langle r_{a}^{e}\right\rangle_{s}$ (a2 and b2). Plots (a1) and (a2) are for the R. sphaerocarpa patch, and plots (b1) and (b2) are for the herbaceous patch. The dashed line is the 1:1 line.

for the R. sphaerocarpa and the herbaceous patch, respectively (Table 4).

When the surface resistances were compared, though $\left\langle r_{s}^{e}\right\rangle_{p}$ was lower than $\left\langle r_{s}^{e}\right\rangle_{s}$, as was the case with the aerodynamic resistances, there was much less difference between them in the $R$. sphaerocarpa patch (around 40\%) than in the herbaceous patch (around 80\%) (Table 4). This can be observed in Fig. 5, where the aggregated surface resistances were plotted against soil moisture $(\theta)$, which soil and plant surface resistances depend on.

In the herbaceous patch, $\left\langle r_{s}^{e}\right\rangle_{p}$ was observed to be much lower than $\left\langle r_{s}^{e}\right\rangle_{s}$ and less dependent on $\theta$, while $\left\langle r_{s}^{e}\right\rangle_{s}$ varied considerably with $\theta$ and covered a wide range of values (hence the high SD in Table 4). In the R. sphaerocarpa patch, $\left\langle r_{s}^{e}\right\rangle_{p}$ and $\left\langle r_{s}^{e}\right\rangle_{s}$ were much closer and varied similarly with $\theta$. 
Table 4. Average $\pm \mathrm{SD}$ (standard deviation) of the $\Delta r$ differences between the effective resistances considered. (a) $R$. sphaerocarpa patch, (b) Herbaceous patch.

\begin{tabular}{|c|c|c|c|c|c|}
\hline \multirow{2}{*}{ (a) } & & \multicolumn{4}{|c|}{$r_{i}$} \\
\hline & $\Delta r(\%)$ & $\left\langle r_{a}^{e}\right\rangle_{s}$ & $r_{a_{1}}^{e}$ & $r_{a_{2}}^{e}$ & $\left\langle r_{s}^{e}\right\rangle_{s}$ \\
\hline \multirow{5}{*}{$r_{j}$} & $\left\langle r_{a}^{e}\right\rangle_{p}$ & $61.8 \pm 5.3$ & $53 \pm 11.8$ & $77.4 \pm 5.7$ & \\
\hline & $\left\langle r_{a}^{e}\right\rangle_{s}$ & & $-28.4 \pm 43.5$ & $38.4 \pm 20.9$ & \\
\hline & $\left\langle\overline{r_{a}^{e}}\right\rangle$ & & $12.4 \pm 27.7$ & $57.9 \pm 13.3$ & \\
\hline & $r_{a_{1}}^{e}$ & & & $52.0 \pm 0.0$ & \\
\hline & $\left\langle r_{s}^{e}\right\rangle_{p}$ & & & & $38.2 \pm 4.1$ \\
\hline
\end{tabular}

\begin{tabular}{|c|c|c|c|c|c|}
\hline \multirow{2}{*}{ (b) } & & \multicolumn{4}{|c|}{$r_{i}$} \\
\hline & $\Delta r(\%)$ & $\left\langle r_{a}^{e}\right\rangle_{s}$ & $r_{a_{1}}^{e}$ & $r_{a_{2}}^{e}$ & $\left\langle r_{s}^{e}\right\rangle_{s}$ \\
\hline \multirow{5}{*}{$r_{j}$} & $\left\langle r_{a}^{e}\right\rangle_{p}$ & $52.9 \pm 4.2$ & $50.3 \pm 14.1$ & $75.3 \pm 7.0$ & \\
\hline & $\left\langle r_{a}^{e}\right\rangle_{s}$ & & $-7.8 \pm 36.7$ & $46.3 \pm 18.2$ & \\
\hline & $\left\langle\overline{r_{a}^{e}}\right\rangle$ & & $21.2 \pm 25.3$ & $60.8 \pm 12.6$ & \\
\hline & $r_{a_{1}}^{e}$ & & & $50.3 \pm 0.1$ & \\
\hline & $\left\langle r_{s}^{e}\right\rangle_{p}$ & & & & $81.9 \pm 10.4$ \\
\hline
\end{tabular}

To understand the differences in aggregated resistances between the two patches, and between surface and aerodynamic resistances, we compared them to the soil and plant resistances (and to the atmospheric aerodynamic resistance, in the case of $\left\langle r_{a}^{e}\right\rangle$ ) in each patch (Figs. 6 and 7).

As seen in Fig. 6, the soil, plant and atmospheric aerodynamic resistances were similar in both patches. The effect of $r_{a}^{p}$ on $\left\langle r_{a}^{e}\right\rangle_{p}$ was stronger in the herbaceous patch, because in the $R$. sphaerocarpa patch $r_{a}^{s u}$ diminished the effect of $r_{a}^{p}$ (according to Eq. 16).

With regard to surface resistances, soil resistances were much higher than plant resistances in the herbaceous patch (Fig. 7). Therefore, in the herbaceous patch, the effect of aggregating resistances in parallel or in series generated wide differences in the effective resistances found, even though $f$ was less than 0.2. However, in the R. sphaerocarpa patch, there was not as much difference between soil and plant resistances (Fig. 7), and $f$ was low (0.17), so the effect of how aggregation was done on the effective surface resistance was not as great in this patch.

Regardless of the type of effective resistance, in all cases aerodynamic resistances were many times lower than surface resistances, and therefore their effect on the estimation of $\lambda E$

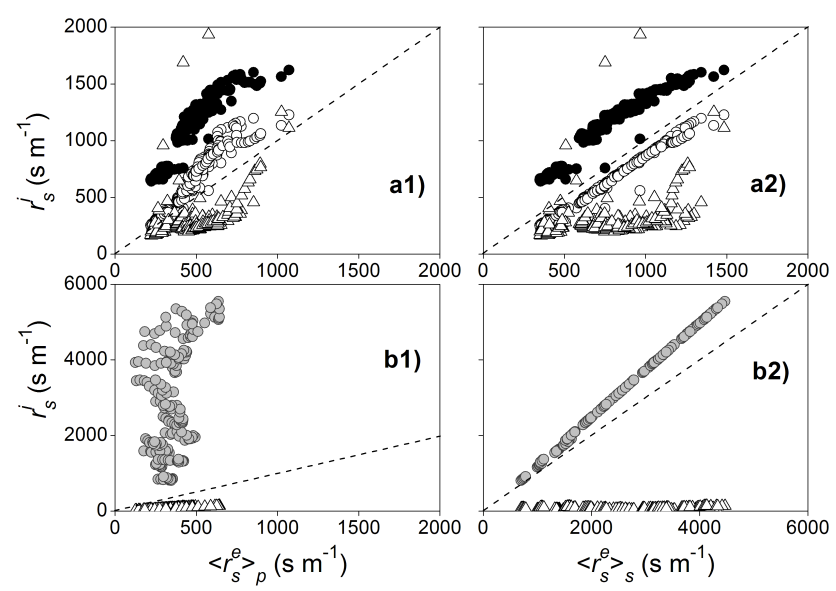

Fig. 7. Surface resistances of the sources $\left(r_{s}^{s u}: \bullet ; r_{s}^{b s}: \bigcirc ; r_{s}^{s}: \bigcirc\right.$ and $\left.r_{s}^{p}: \Delta\right)$ plotted against the effective aggregated surface resistances: $\left\langle r_{s}^{e}\right\rangle_{p}\left(\mathbf{a} \mathbf{1}\right.$ and b1) and $\left\langle r_{s}^{e}\right\rangle_{s}$ (a2 and b2). Plots (a1) and (a2) are for the $R$. sphaerocarpa patch, and plots $\mathrm{b} 1$ and $\mathrm{b} 2$ for the herbaceous patch. The dashed line is the 1:1 line.

was also slight, as previously reported by other authors (Verhoef and Allen, 1998). 


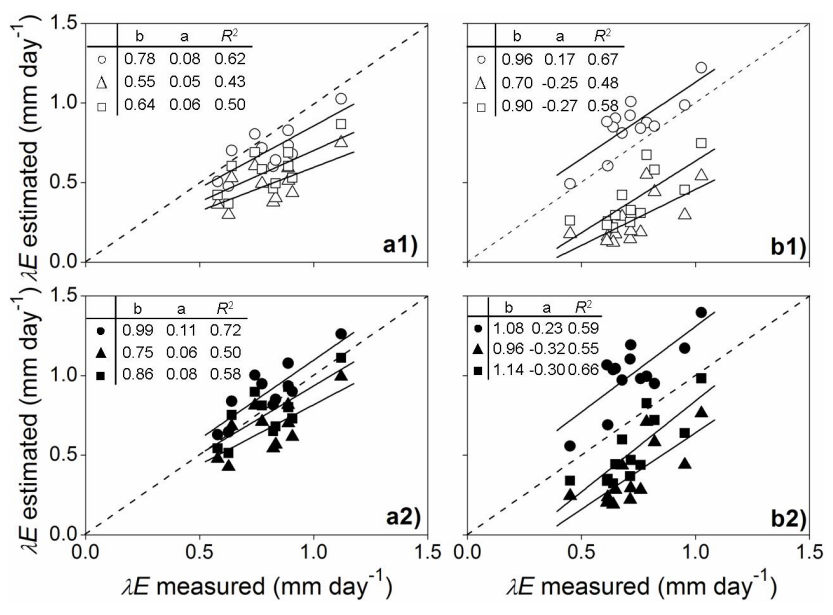

Fig. 8. Regressions between estimated and measured $\lambda E$ for the $R$. sphaerocarpa patch (a1 and a2), and the herbaceous patch (b1 and b2). $\lambda E$ was estimated using different combinations of effective surface and aerodynamic resistances: $\left\langle r_{s}^{e}\right\rangle_{p}$ and $r_{a 1}^{e}(\bigcirc) ;\left\langle r_{s}^{e}\right\rangle_{p}$ and $r_{a 2}^{e}(\bullet) ;\left\langle\overline{r_{s}^{e}}\right\rangle$ and $r_{a 1}^{e}(\square) ;\left\langle\overline{r_{s}^{e}}\right\rangle$ and $r_{a 2}^{e}(\mathbf{\square}) ;\left\langle r_{s}^{e}\right\rangle_{s}$ and $r_{a 1}^{e}(\Delta) ;\left\langle r_{s}^{e}\right\rangle_{s}$ and $r_{a 2}^{e}(\boldsymbol{\Lambda})$. The regression lines (solid lines) and 1:1 line (dashed line) are shown, as well as the values of slope (b), intercept (a) and $R^{2}$ for each of the regressions.

4.2 Comparing $\lambda E$ estimated using the effective resistances and $\lambda E$ measured in each patch

$\lambda E$ estimated with Eq. (6) was compared to $\lambda E$ measured in each patch. $\lambda E$ was estimated using the aggregated surface resistances $\left(\left\langle r_{s}^{e}\right\rangle_{p},\left\langle r_{s}^{e}\right\rangle_{s}\right.$ and $\left.\left\langle\overline{r_{s}^{e}}\right\rangle\right)$ combined with the effective aerodynamic resistances calculated with Eq. (4), $r_{a 1}^{e}$ and $r_{a 2}^{e}$, (Fig. 8), and the aggregated aerodynamic resistances, $\left\langle r_{a}^{e}\right\rangle_{p},\left\langle r_{a}^{e}\right\rangle_{s}$ and $\left\langle\overline{r_{a}^{e}}\right\rangle$ (Fig. 9).

First of all, comparing the results for each patch, the estimates found using different $\left\langle r_{s}^{e}\right\rangle$ in the $R$. sphaerocarpa patch were observed to be similar (Figs. 8a1 and a2 and Figs. 9a1 and a2). Estimated average daily $\lambda E$ ranged from $0.9 \mathrm{~mm} \mathrm{day}^{-1}$ using $\left\langle r_{s}^{e}\right\rangle_{p}$ with $r_{a 2}^{e}$ to $0.49 \mathrm{~mm} \mathrm{day}^{-1}$ using $\left\langle r_{s}^{e}\right\rangle_{s}$ with $r_{a 1}^{e}$; and from $0.77 \mathrm{~mm} \mathrm{day}^{-1}$ using $\left\langle r_{s}^{e}\right\rangle_{p}$ with $\left\langle r_{a}^{e}\right\rangle_{s}$, to $0.36 \mathrm{~mm} \mathrm{day}^{-1}$ using $\left\langle r_{s}^{e}\right\rangle_{s}$ with $\left\langle r_{a}^{e}\right\rangle_{p}$. However, in the herbaceous patch, there was clearly a wide difference between $\lambda E$ estimated with $\left\langle r_{s}^{e}\right\rangle_{p}$ and with $\left\langle r_{s}^{e}\right\rangle_{s}$ or $\left\langle\overline{r_{s}^{e}}\right\rangle$, regardless of the aerodynamic effective resistances used (Figs. 8b1 and b2 and Figs. 9b1 and b2). Estimated average daily $\lambda E$ ranged from $1.01 \mathrm{~mm}$ day $^{-1}$ using $\left\langle r_{s}^{e}\right\rangle_{p}$ with $r_{a 2}^{e}$, to $0.26 \mathrm{~mm} \mathrm{day}^{-1}$ using $\left\langle r_{s}^{e}\right\rangle_{s}$ with $r_{a 1}^{e}$; and from $0.88 \mathrm{~mm} \mathrm{day}^{-1}$ using $\left\langle r_{s}^{e}\right\rangle_{p}$ with $\left\langle r_{a}^{e}\right\rangle_{s}$, to $0.18 \mathrm{~mm} \mathrm{day}^{-1}$ us$\operatorname{ing}\left\langle r_{s}^{e}\right\rangle_{s}$ with $\left\langle r_{a}^{e}\right\rangle_{p}$.

For comparing the estimated and measured $\lambda E$, on one hand we calculated the root mean squared error (RMSE) as:

$\mathrm{RMSE}=\sqrt{\frac{1}{n} \sum\left(\lambda E_{i}-\lambda E_{t}\right)^{2}}$

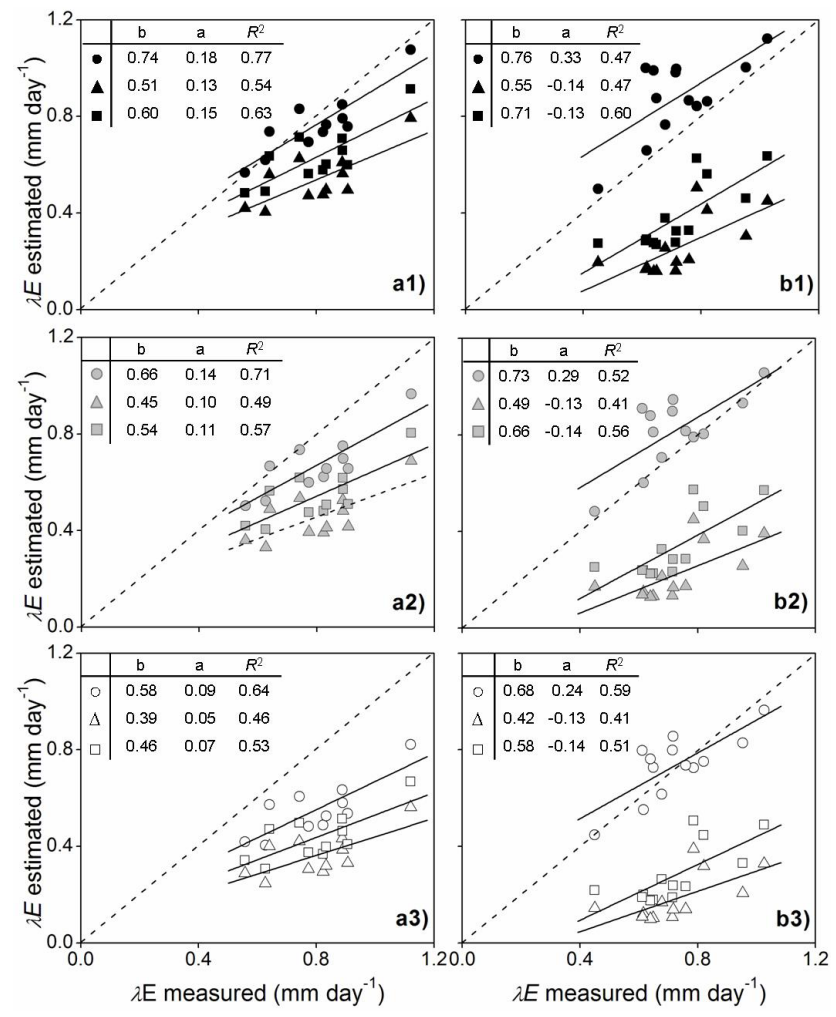

Fig. 9. Regressions between estimated and measured $\lambda E$ for the $R$. sphaerocarpa patch (panels $\mathbf{a}_{1}, \mathbf{a}_{2}$, and $\mathbf{a}_{3}$ ) and the herbaceous patch (panels $\mathbf{b}_{1}, \mathbf{b}_{2}$, and $\mathbf{b}_{3}$ ). $\lambda E$ was estimated using different combinations of effective surface and aerodynamic resistances: $\left\langle r_{s}^{e}\right\rangle_{p}$ and $\left\langle r_{a}^{e}\right\rangle_{s}(\bullet) ;\left\langle r_{s}^{e}\right\rangle_{p}$ and $\left\langle\overline{r_{a}^{e}}\right\rangle(\bigcirc) ;\left\langle r_{s}^{e}\right\rangle_{p}$ and $\left\langle r_{a}^{e}\right\rangle_{p}(\bigcirc) ;\left\langle\overline{r_{s}^{e}}\right\rangle$ and $\left\langle r_{a}^{e}\right\rangle_{s}(\boldsymbol{\square}) ;\left\langle\overline{r_{s}^{e}}\right\rangle$ and $\left\langle\overline{r_{a}^{e}}\right\rangle(\square) ;\left\langle\overline{r_{s}^{e}}\right\rangle$ and $\left\langle r_{a}^{e}\right\rangle_{p}(\square) ;\left\langle r_{s}^{e}\right\rangle_{s}$ and $\left\langle r_{a}^{e}\right\rangle_{s}(\mathbf{\Delta})$; $\left\langle r_{s}^{e}\right\rangle_{s}$ and $\left\langle\overline{r_{a}^{e}}\right\rangle(\triangle) ;\left\langle r_{s}^{e}\right\rangle_{s}$ and $\left\langle r_{a}^{e}\right\rangle_{p}(\Delta)$. The regression lines (solid lines) and 1:1 line (dashed line) are shown, as well as the values of slope (b), intercept (a) and $R^{2}$ for each of the regressions.

where $\lambda E_{i}$ is the estimated value, $\lambda E_{t}$ is the measured value and $n$ is the number of days considered.

On the other hand, we calculated the mean percentage error (MPE) and the mean absolute percentage error (MAPE), to have a better notion of the magnitude of the differences between the estimated and the measured $\lambda E$. We calculated these errors as follows:

$$
\begin{aligned}
& \mathrm{MPE}=\frac{1}{n} \sum\left[\left(\frac{\lambda E_{i}-\lambda E_{t}}{\lambda E_{t}}\right) \times 100\right] \\
& \mathrm{MAPE}=\frac{1}{n} \sum\left[\left(\frac{\left|\lambda E_{i}-\lambda E_{t}\right|}{\lambda E_{t}}\right) \times 100\right]
\end{aligned}
$$

Results are shown on Tables 5 and 6.

In the $R$. sphaerocarpa patch, effective resistances $\left\langle r_{s}^{e}\right\rangle_{p}$ and $\left\langle r_{a}^{e}\right\rangle_{s}$ generated the best overall estimates of $\lambda E$ compared to the measured values, with a MAPE of less than $10 \%$ (Table 6), which is within the energy balance closure 
Table 5. Mean percentage error (MPE in \%), mean absolute percentage error (MAPE in \%), and root mean square error (RMSE in mm day ${ }^{-1}$ ) of the daily estimated $\lambda E$ with the effective aggregated surface resistances and the effective aerodynamic resistances calculated with Eq. (4), for each patch. For MPE and MAPE the standard deviation is also indicated.

\begin{tabular}{lcccccc}
\hline & \multicolumn{3}{c}{$R$ sphaerocarpa patch } & \multicolumn{3}{c}{ Herbaceous patch } \\
& MPE & MAPE & RMSE & MPE & MAPE & RMSE \\
\hline$\lambda E\left\langle r_{s}^{e}\right\rangle_{p} r_{a_{1}}^{e}$ & $-12 \pm 13$ & $15 \pm 8$ & 0.14 & $20 \pm 16$ & $21 \pm 15$ & 0.17 \\
$\lambda E\left\langle r_{s}^{e}\right\rangle_{s} r_{a_{1}}^{e}$ & $-39 \pm 13$ & $39 \pm 13$ & 0.34 & $-65 \pm 16$ & $65 \pm 16$ & 0.47 \\
$\lambda E\left\langle\overline{r_{s}^{e}}\right\rangle_{r_{1}}^{e}$ & $-28 \pm 13$ & $28 \pm 13$ & 0.25 & $-48 \pm 16$ & $48 \pm 16$ & 0.36 \\
$\lambda E\left\langle r_{s}^{e}\right\rangle_{p} r_{a_{2}}^{e}$ & $13 \pm 13$ & $13 \pm 13$ & 0.13 & $41 \pm 21$ & $41 \pm 21$ & 0.32 \\
$\lambda E\left\langle r_{s}^{e}\right\rangle_{s} r_{a_{2}}^{e}$ & $-16 \pm 16$ & $19 \pm 11$ & 0.18 & $-50 \pm 19$ & $50 \pm 19$ & 0.37 \\
$\lambda E\left\langle\overline{r_{s}^{e}}\right\rangle r_{a_{2}}^{e}$ & $-4 \pm 15$ & $13 \pm 8$ & 0.12 & $-29 \pm 18$ & $30 \pm 16$ & 0.23 \\
\hline
\end{tabular}

Table 6. Mean percentage error (MPE in \%), mean absolute percentage error (MAPE in \%), and root mean square error (RMSE in mm day ${ }^{-1}$ ) of the daily estimated $\lambda E$ with the different effective aggregated surface and aerodynamic resistances for each patch. For MPE and MAPE the standard deviation is also indicated.

\begin{tabular}{lcccccc}
\hline & \multicolumn{3}{c}{$R$. sphaerocarpa patch } & \multicolumn{3}{c}{ Herbaceous patch } \\
& MPE & MAPE & RMSE & MPE & MAPE & RMSE \\
\hline$\lambda E\left\langle r_{s}^{e}\right\rangle_{p}\left\langle r_{a}^{e}\right\rangle_{p}$ & $-31 \pm 10$ & $31 \pm 10$ & 0.26 & $3 \pm 14$ & $12 \pm 8$ & 0.10 \\
$\lambda E\left\langle r_{s}^{e}\right\rangle_{p}\left\langle\overline{r_{a}^{e}}\right\rangle$ & $-15 \pm 10$ & $16 \pm 8$ & 0.15 & $14 \pm 17$ & $15 \pm 16$ & 0.14 \\
$\lambda E\left\langle r_{s}^{e}\right\rangle_{p}\left\langle r_{a}^{e}\right\rangle_{s}$ & $-3 \pm 10$ & $9 \pm 5$ & 0.08 & $23 \pm 20$ & $23 \pm 20$ & 0.20 \\
$\lambda E\left\langle r_{s}^{e}\right\rangle_{s}\left\langle r_{a}^{e}\right\rangle_{p}$ & $-54 \pm 9$ & $54 \pm 9$ & 0.45 & $-75 \pm 11$ & $75 \pm 11$ & 0.55 \\
$\lambda E\left\langle r_{s}^{e}\right\rangle_{s}\left\langle\overline{r_{a}^{e}}\right\rangle$ & $-42 \pm 10$ & $42 \pm 10$ & 0.36 & $-70 \pm 12$ & $70 \pm 12$ & 0.52 \\
$\lambda E\left\langle r_{s}^{e}\right\rangle_{s}\left\langle r_{a}^{e}\right\rangle_{s}$ & $-32 \pm 11$ & $32 \pm 11$ & 0.28 & $-65 \pm 12$ & $65 \pm 12$ & 0.48 \\
$\lambda E\left\langle\overline{r_{s}^{e}}\right\rangle\left\langle r_{a}^{e}\right\rangle_{p}$ & $-45 \pm 10$ & $45 \pm 10$ & 0.38 & $-62 \pm 12$ & $62 \pm 12$ & 0.45 \\
$\lambda E\left\langle\overline{r_{s}^{e}}\right\rangle\left\langle\overline{r_{a}^{e}}\right\rangle$ & $-32 \pm 10$ & $32 \pm 10$ & 0.28 & $-54 \pm 12$ & $54 \pm 12$ & 0.40 \\
$\lambda E\left\langle\overline{r_{s}^{e}}\right\rangle\left\langle r_{a}^{e}\right\rangle_{s}$ & $-20 \pm 11$ & $20 \pm 11$ & 0.19 & $-48 \pm 12$ & $48 \pm 12$ & 0.35 \\
\hline
\end{tabular}

of the measured data, and a RMSE of $0.08 \mathrm{~mm} \mathrm{day}^{-1}$. However, when using $r_{a 2}^{e}$ combined with $\left\langle r_{s}^{e}\right\rangle_{p}$ or even with $\left\langle\overline{r_{s}^{e}}\right\rangle$, $\lambda E$ estimates differed by only $13 \%$ from the measured $\lambda E$ (Table 5), though the RMSE was higher than when using the aggregated resistances $\left(0.13\right.$ and $\left.0.12 \mathrm{~mm} \mathrm{day}^{-1}\right)$. Using $r_{a 1}^{e}$ again combined with $\left\langle r_{s}^{e}\right\rangle_{p}$ (Table 5), the estimated $\lambda E$ was fairly close to measured $\lambda E$, with a $15 \%$ difference, the RMSE being somewhat higher $\left(0.14 \mathrm{~mm} \mathrm{day}^{-1}\right)$. Therefore, these results showed that the effective surface resistances that led to the best estimates of $\lambda E$ were $\left\langle r_{s}^{e}\right\rangle_{p}$ (the use of the other types of effective surface resistances clearly underestimated $\lambda E$, with the negative values of MPE similar to the MAPE values), and the aerodynamic resistances were $\left\langle r_{a}^{e}\right\rangle_{s}$ and $r_{a 2}^{e}$.

In the herbaceous patch, regardless of the effective aerodynamic resistances used, $\left\langle r_{s}^{e}\right\rangle_{p}$ were the effective surface resistances that provided the best estimates of $\lambda E$ compared to measured values, as was also the case in the $R$. sphaerocarpa patch. The combinations of $\left\langle r_{s}^{e}\right\rangle_{p}$ with $\left\langle r_{a}^{e}\right\rangle_{p}$ or $\left\langle\overline{r_{a}^{e}}\right\rangle$ generated the estimates of $\lambda E$ closest to the measured values, with average differences of $12 \%$ and $15 \%$, respectively (Table 6). 
However, the RMSE was smaller for $\left\langle r_{s}^{e}\right\rangle_{p}$ with $\left\langle r_{a}^{e}\right\rangle_{p}$ than for $\left\langle r_{s}^{e}\right\rangle_{p}$ with $\left\langle\overline{r_{a}^{e}}\right\rangle\left(0.10 \mathrm{~mm} \mathrm{day}^{-1}\right.$ and $0.14 \mathrm{~mm} \mathrm{day}^{-1}$, respectively), the latter clearly overestimating the measured values (MAPE equal to MPE). The use of $\left\langle r_{s}^{e}\right\rangle_{s}$ or $\left\langle\overline{r_{s}^{e}}\right\rangle$ clearly underestimated $\lambda E$ (Table 6). When aerodynamic resistances calculated with Eq. (4) were used (Table 5), the $\lambda E$ estimates differed widely from the measured $\lambda E$. Using $\left\langle r_{s}^{e}\right\rangle_{p}$, the $\lambda E$ obtained overestimated measured $\lambda E$ in $20 \%$ when combined with $r_{a 1}^{e}$ and in $41 \%$ when combined with $r_{a 2}^{e}$, the RMSE being $0.17 \mathrm{~mm} \mathrm{day}^{-1}$ and $0.47 \mathrm{~mm} \mathrm{day}^{-1}$, respectively. As $r_{a 2}^{e}$ was calculated with a $k B^{-1}$ measured in a patch of $R$. sphaerocarpa, this resistance would not be expected to be suitable for a patch of herbaceous plants, with very different aerodynamic parameters. The rest of combinations of effective resistances clearly underestimated $\lambda E$ (Table 5).

It may be observed that the SDs of MPE and also of MAPE were very high, showing some dispersion of the results. This was because we used measured values of $\lambda E$ as well as of the variables and parameters used in its estimation. Considering that the use of effective parameters involved a simplification of the spatial heterogeneity in the patches, an error in the estimations was expected. However, as the use of effective parameters and the aggregation of spatial heterogeneity are necessary to model the fluxes at higher scales of heterogeneity, the results reported in this paper are important because they show the effect of these effective parameters at patchscale and using measured values.

The overall results show that the type of effective surface resistances used was what most affected the $\lambda E$ estimates. Thus, the surface resistances aggregated in parallel gave the best estimates of $\lambda E$ in both patches. This suggests that this type of aggregation is the most suitable for estimating patchscale effective surface resistances, which does not coincide with the idea that the average of resistances aggregated in series and in parallel $\left(\left\langle\overline{r^{e}}\right\rangle\right)$, as proposed by Blyth et al. (1993), would generate the best estimates of $\lambda E$. It should be noted that to estimate $\lambda E$, these authors used the aggregation of theoretical resistances in two patches, while we analysed the aggregation of measured soil and plant resistances. Moreover, the best estimates of $\lambda E$ obtained with parallel aggregation of surface resistances, may be due to the fact that soil resistances are higher than plant resistances, and the vegetative cover fraction is very small, which is characteristic of semiarid areas. Parallel aggregation of the resistances attenuated the effect of the high soil resistances.

Results for aerodynamic resistances were not the same in the two patches. While in the R. sphaerocarpa patch the effective aerodynamic resistances aggregated in series produced the best estimates of $\lambda E$, in the herbaceous patch the effective aerodynamic resistances aggregated in parallel, or even the average of resistances aggregated in parallel and in series, gave acceptable results. Other authors, like Chehbouni et al. $(1997,2000)$ have aggregated resistances in parallel in two patches of different types of vegetation to estimate the aggregated effective aerodynamic resistance for sensible heat.

These results show that, again the most suitable aggregation method for estimating effective resistances changes depending on the type of resistance, on the scale of heterogeneity and on the type of vegetation.

In both patches, $\lambda E$ obtained with the aerodynamic resistances calculated directly from wind speed and $k B^{-1}$ had a higher error (both MAPE and RMSE) compared to measured $\lambda E$, than $\lambda E$ obtained with aggregated resistances. However, when using a $k B^{-1}$ measured in a $R$. sphaerocarpa patch, the $\lambda E$ estimates in a nearby patch were quite similar to the measured $\lambda E$ (MAPE around 13\% and RMSE around $0.12 \mathrm{~mm} \mathrm{day}^{-1}$ ). Using a generic $k B^{-1}$, used by other authors in other patches of vegetation (Blyth, 1997), estimates of $\lambda E$ had an error of around $20 \%$ compared to the measurements in both patches. This method of estimating the effective aerodynamic resistances for the patch has the advantage of not requiring complex measurements or parameterisations, though there is a wider error than with aggregated soil and plant aerodynamic resistances.

\section{Conclusions}

- In a semi-arid area, where surface resistances are very high, the patch-scale effective surface resistance affects the estimation of evapotranspiration the most at this scale.

- The type of aggregation of soil and plant resistances suitable for calculating the effective resistances in the patch varies depending on the type of resistance (i.e., surface or aerodynamic), and the type of vegetation predominant in the patch, which determines the number of soil and plant resistances considered.

- For a semi-arid area like the one we studied, the aggregation of soil, plant and atmospheric aerodynamic resistances for calculating the effective aerodynamic resistance gives better results than calculating it directly from the wind speed at reference height and the parameter $k B^{-1}$.

Acknowledgements. This work received financial support from several different research projects: the PROBASE (ref.: CGL200611619/HID) and CANOA (ref.: CGL2004-04919-C02-01/HID) projects funded by the Spanish Ministry of Education and Science; and the BACAEMA ("Balance de carbono y de agua en ecosistemas de matorral mediterráneo en Andalucía: Efecto del cambio climático", RNM-332) and CAMBIO ("Efectos del cambio global sobre la biodiversidad y el funcionamiento ecosistémico mediante la identificación de áreas sensibles y de referencia en el SE ibérico", RNM 1280) projects funded by the regional government Junta de Andalucía. The first author enjoyed a pre-doctoral grant from the Spanish Ministry of Science and Technology. The authors would like to thank A. Durán Sánchez and M. Guerrero Berenguel 
for their invaluable help in the field work, and D. Fuldauer for correcting and improving the English of the text.

Edited by: H. Vereecken

\section{References}

Alados-Arboledas, L., Olmo, F. J., Puigdefábregas, J., Domingo, F., and Villagarcía, L.: Using Infrared Remote Sensing for the Estimation of Sensible Heat Flux over Sparse Vegetation in Southeastern Spain, 1-2, Lagos, 2nd Asamblea Hispano Portuguesa de Geodesia y Geofísica, 2000.

Arain, M. A., Shuttleworth, W. J., Yang, Z.- L., Michaud, J., and Dolman, J.: Mapping surface-cover parameters using aggregation rules and remotely sensed cover classes, Q. J. Roy. Meteor. Soc., 123, 2325-2348, 1997.

Baldocchi, D. D., Luxmoore, J., and Hatfield, J. L.: Discerning the forest from the trees: an essay on scaling canopy stomatal conductance, Agr. Forest Meteorol., 54, 197-226, 1991.

Baldocchi, D. D., Falge, E., Gu, L., et al.: FLUXNET: a new tool to study the temporal and spatial variability of ecosystem-scale carbon dioxide, water vapor and energy flux densities, B. Am. Meteorol. Soc., 82, 2415-2434, 2001.

Blyth, E. M., Dolman, A. J., and Wood, N.: Effective resistance to sensible- and latent-heat flux in heterogeneous terrain, Q. J. Roy. Meteor. Soc., 119, 423-442, 1993.

Blyth, E. M.: Using a simple SVAT scheme to describe the effect of scale on aggregation, Bound.-Lay. Meteorol., 72, 267-285, 1995.

Blyth, E. M.: Representing heterogeneity at the southern super site with average surface paramenters, J. Hydrol., 188-189, 869-877, 1997.

Brenner, A. J. and Incoll, L. D.: The effect of clumpling and stomatal response on evaporation from sparsely vegetated shrublands, Agr. Forest Meteorol., 84, 187-205, 1997.

Brutsaert, W.: Heat and mass transfer to and from surfaces with dense vegetation or similar permeable roughness., Bound.-Lay. Meteorol., 16, 365-388, 1979.

Cantón, Y., Solé-Benet, A., and Domingo, F.: Temporal and spatial patterns of soil moisture in semiarid badlands of SE Spain, J. Hydrol., 285, 199-214, 2004.

Chehbouni, A., Lo Seen, D., Njoku, E. G., Lhomme, J. P., Monteny, B. A., and Kerr, Y. H.: Estimation of sensible heat flux over sparsely vegetated surfaces, J. Hydrol., 188-189, 855-868, 1997.

Chehbouni, A., Watts, C., Kerr, Y. H., Dedieu, G., Rodriguez, J. C., Santiago, F., Cayrol, P., Boulet, G., and Goodrich, D. C.: Methods to aggregate turbulent fluxes over heterogeneous surfaces: application to SALSA data ser in Mexico, Agr. Forest Meteorol., 105, 133-144, 2000.

Choudhoury, B. J. and Monteith, J. L.: A four-layer model for the heat budget of homogeneous land surfaces, Q. J. Roy. Meteor. Soc., 114, 373-398, 1988.

Daamen, C. C., Simmonds, L. P., Wallace, J. S., Laryea, K. B., and Sivakumar, M. V. K.: Use of microlysimeters to measure evaporation from sandy soils, Agr. Forest Meteorol., 65, 159173, 1993.

Dolman, A. J.: A note on areally-averaged evaporation and the value of the effective surface conductance, J. Hydrol., 138, 583$589,1992$.
Dolman, A. J.: A multiple-source land surface energy balance model for use in general circulation models, Agr. Forest Meteorol., 65, 21-45, 1993.

Dolman, A. J. and Blyth, E. M.: Patch scale aggregation of heterogeneous land surface cover for mesoscale meteorological models, J. Hydrol., 190, 252-268, 1997.

Domingo, F., Van Gardingen, P. R., and Brenner, A. J.: Leaf boundary layer conductance of two native species in southeast Spain, Agr. Forest Meteorol., 81, 179-199, 1996.

Domingo, F., Villagarcía, L., Brenner, A. J., and Puigdefábregas, J.: Evapotranspiration model for semi-arid shrub-lands tested against data from SE Spain, Agr. Forest Meteorol., 95, 67-84, 1999.

Domingo, F., Villagarcía, L., Brenner, A. J., and Puigdefábregas, J.: Measuring and modelling the radiation balance of a heterogeneous shrubland, Plant Cell Environ., 23, 27-38, 2000.

Domingo, F., Villagarcía, L. Boer, M. M., Alados-Arboledas, L., and Puigdefábregas, J.: Evaluating the long-term water balance of arid zone stream bed vegetation using evapotranspiration modelling and hillslope runoff measurements, J. Hydrol., 243, 17-30, 2001.

Fiedler, F. and Panofsky, H.: The geostrophic drag coefficient and the effective roughness length, Q. J. Roy. Meteor. Soc., 98, 213 220, 1976.

Fuchs, M.: Heat flux, in: Methods of Soil Analysis Part I. Physical and Mineralogical Methods, Vol. 2, edited by: Klute, A., American Society of Agronomy, Madison, WI., 957-968, 1986.

Garrat, J. R.: Transfer characteristics for a heterogeneous surface of large aerodynamic roughness, Q. J. Roy. Meteor. Soc., 104, 491-502, 1978.

Goeckede, M., Rebmann, C., and Foken, T.: A combination of quality assessment tools for eddy covariance measurements with footprint modelling for the characterisation of complex sites, Agr. Forest Meteorol., 127, 175-188, 2004.

Gutiérrez, L.: Estructura y Productividad de la vegetación de estepa mediterránea semiárida en relación con la variabilidad climática: el sistema de ladera en Rambla Honda (Almería), PhD Thesis, Universidad de Almería, Almería, Spain, 2000.

Haase, P., Pugnaire, F. I., Fernández, E. M. Puigdefábregas, J., Clark, S. C., and Incoll, L. D.: An investigation of rooting depth of the semi-arid shrub Retama sphaerocarpa (L.) Boiss. by labelling of ground water with a chemical tracer, J. Hydrol., 177, 23-31, 1996.

Jones, H. G.: Plants and microclimate: a quantitative approach to environmental plant physiology, Cambridge University Press, London, 1992.

Kowalski, A. S., Anthoni, P. M., Vong, R. J., Delany, A. C., and Maclean, G. D.: Deployment and Evaluation of a System for Ground-Based Measurement of Cloud Liquid Water Turbulent Fluxes, J. Atmos. Ocean. Tech., 14(3), 468-479, 1997.

Kustas, W. P., Choudhury, B. J., Moran, M. S., Reginato, R. J., Jackson, R. D., Gay, L. W., and Weaver, H. L.: Determination of sensible heat flux over sparse canopy using thermal infrared data, Agr. Forest Meteorol., 44, 197-216, 1989.

Mahrt, L.: Surface Heterogeneity and Vertical Structure of the Boundary Layer, Bound.-Lay. Meteorol., 96, 33-62, 2000.

Mason, J. P.: The formation of areally-averaged roughness lengths, Q. J. Roy. Meteor. Soc., 114, 399-420, 1988.

Massman, W. J.: A surface energy balance method for partition- 
ing evapotranspiration data into plant and soil components for a surface with partial canopy cover, Water Resour. Res., 28, 17231732, 1992.

McInnes, K. J., Heilman, J. L., and Lascano, R. J.: Aerodynamic conductances at the soil surface in a vineyard, Agr. Forest Meteorol., 79, 29-37, 1996.

McInnes, K. J., Heilman, J. L., and Savage, M. J.: Aerodynamic conductances along a bare ridge-furrow tilled soil surface, Agr. Forest Meteorol., 68. 119-131, 1994.

McNaughton, K. G.: Effective stomatal and boundary-layer resistance of heterogeneous surfaces, Plant Cell Environ., 17, 10611068, 1994.

Mölder, M. and Lindroth, A.: Dependence of $\mathrm{kB}^{-1}$ factor on roughness Reynolds number for barley and pasture, Agr. Forest Meteorol., 106, 147-152, 2001.

Monteith, J. L.: Evaporation and Environment, Sym. Soc. Exp. Biol., 19, 205-234, 1965.

Noilhan, J., Lacarrère, P., Dolman, A. J., and Blyth, E. M.: Defining area-average parameters in meteorological models for land surfaces with meso-scale heterogeneity, J. Hydrol., 190, 302-316, 1997.

Owen, P. R. and Thomson, W. R.: Heat transfer across rough surfaces, J. Fluid Mech., 15, 321-334, 1963.

Puigdefábregas, J., Alonso, J. M., Delgado, L., Domingo, F., Cueto, M., Gutiérrez, L., Lázaro, R., Nicolau, J. M., Sánchez, G., Solé, A., and Vidal, S.: The Rambla Honda field site: interactions of soil and vegetation along a catena in semi-arid Spain, in: Mediterranean desertification and land use, edited by: Brandt, J. and Thornes, J. B., John Wiley \& Sons, Ltd. Chischester, UK, 137-168, 1996.

Puigdefábregas, J. and Sánchez, G.: Geomorphological implications of vegetation patchiness on semi- arid slopes, Adv. Hillslope Processes, 2, 1027-1060, 1996.

Puigdefábregas, J., Del Barrio, G., Boer, M. M., Gutiérrez, L., and Solé, A.: Differential responses of hillslope and channel elements to rainfall events in a semi-arid area, Geomorphology, 23, 337-351, 1998.

Puigdefábregas, J., Solé, A., Gutiérrez, L., Del Barrio, G., and Boer, M. M.: Scales and processes of water and sediment redistribution in drylands: results from the Rambla Honda field site in Shoutheast Spain, Earth Sci. Rev., 48, 39-70, 1999.

Qualls, R. J. and Brutsaert, W.: The effect of vegetation density on the parameterization of scalar roughness to estimate spatially distributed sensible heat fluxes, Water Resour. Res., 32(3), 645$652,1995$.

Raupach, M. R.: Vegetation-atmosphere interaction and surface conductance at leaf, canopy, and regional scales, Agr. Forest Meteorol., 73, 151-179, 1995.
Schmid, H. P.: Source areas for scalars and scalar fluxes, Bound.Lay. Meteorol., 67, 293-318, 1994.

Schmid, H. P.: Experimental design for flux measurements: matching scales of observations and fluxes, Agr. Forest Meteorol., 87, 179-200, 1997.

Scott, R. L., Watts; C. J., Payan, J. G., Edward, E., Goodrich, D. C., Williams, D., and Shuttleworth, W. J.: The understory and overstory partitioning of energy and water fluxes in an open canopy, semiarid woodland, Agr. Forest Meteorol., 114, 127-139, 2003.

Shuttleworth,W. J., Yang, Z.- L., and Arain, M. A.: Aggregation rules for surface parameters in global models, Hydrol. Earth Syst. Sci., 2, 217-226, 1997, http://www.hydrol-earth-syst-sci.net/2/217/1997/.

Shuttleworth, W. J. and Gurney, R. J.: The theoretical relationships between foliage temperature and canopy resistance in sparse crops, Q. J. Roy. Meteor. Soc., 116, 497-519, 1990.

Shuttleworth, W. J. and Wallace, J. S.: Evaporation from sparse crops, an energy combination theory, Q. J. Roy. Meteor. Soc., 3, 839-855, 1985.

Tanner, B. D., Swiatek, E., and Green, J. P.: Density fluctuations and use of the krypton hygrometer in surface flux measurements, in: Proc. Management of Irrigation and Drainage Systems, ASCE, edited by: Allen, R. G. and Neale, C. M. U., Park City, UT, 105-112, 1993.

Van den Hurk, B. J. J. M. and McNaughton, K. G.: Implementation of near-field dispersion in a sample two-layer surface resistance model, J. Hydrol., 166, 293-311, 1995.

Verhoef, A. and Allen, S. J.: The relative importance of surface and aeordynamic resistances in a multi-source energy- $\mathrm{CO}_{2}$ model, Phys. Chem. Earth, 23, 459-463, 1998.

Verhoef, A. and Allen, S. J.: A SVAT scheme describing energy and $\mathrm{CO} 2$ fluxes for multi-component vegetation: calibration and test for a Sahelian savannah, Ecological Modelling, 127, 245-267, 2000.

Verma, S. B.: Aerodynamic Resistances to Transfers of Heat, Mass and Momentum, IAHS Publ. Vancouver, 177, 13-20, 1989.

Vidal, S.: A device for simultaneous measurement of soil moisture and electrical conductivity, Patent no. 9401681, 1994.

Vidal, S., Domingo, F., Solé-Benet, A., and Puigdefábregas, J.: Desarrollo y calibración de un nuevo sensor de humedad de suelo, in: IV Simposio sobre el Agua en Andalucía, Almería, Spain, vol I, 101-109, 1996.

Webb, E. K., Pearman, G. I., and Leuning, R.: Correction of flux measurements for density effects fue to heat and water vapour transfer, Q. J. Roy. Meteor. Soc.., 106, 85-100, 1980.

Wieringa, J.: Roughness dependent geographical interpolation of surface wind speed averages, Q. J. Roy. Meteor. Soc., 112, 867889, 1986. 